\title{
ROS-Induced DCTPP1 Upregulation Contributes to Cisplatin Resistance in Ovarian Cancer
}

\author{
Yu Wang ${ }^{1 \dagger}$, Peishi Chen ${ }^{2 \dagger}$, Xueping Chen ${ }^{1}$, Daoyuan Gong ${ }^{3}$, Yingsong $\mathrm{Wu}^{2}$, Liping Huang ${ }^{1 *}$ \\ and Yao Chen ${ }^{2 *}$ \\ ${ }^{1}$ Obstetrics and Gynecology Center, Nanfang Hospital, Guangzhou, China, ${ }^{2}$ School of Medical Laboratory and Biotechnology, \\ Southern Medical University, Guangzhou, China, ${ }^{3}$ Guangzhou Customs District technology center, Foshan, China
}

\section{OPEN ACCESS}

Edited by:

Mingzhen Zhang,

Xi'an Jiaotong University, China

Reviewed by:

Xiaoguang Liu,

University of Texas MD Anderson

Cancer Center, United States

Qiuran Xu,

Zhejiang Provincial People's Hospital,

China

*Correspondence:

Liping Huang

Lipinghuang2015@yeah.net

Yao Chen

yaoc@smu.edu.cn

${ }^{\text {t}}$ These authors have contributed equally to this work

Specialty section:

This article was submitted to

Nanobiotechnology,

a section of the journal

Frontiers in Molecular Biosciences

Received: 17 December 2021

Accepted: 20 January 2022

Published: 09 February 2022

Citation:

Wang $Y$, Chen $P$, Chen $X$, Gong $D$, Wu $Y$, Huang $L$ and Chen $Y$ (2022) ROS-Induced DCTPP1 Upregulation Contributes to Cisplatin Resistance in

Ovarian Cancer.

Front. Mol. Biosci. 9:838006. doi: 10.3389/fmolb.2022.838006
Cisplatin resistance hinders the improvement of the prognosis of patients with ovarian cancer. Cisplatin induces cancer cell apoptosis by inducing reactive oxygen species (ROS). dCTP pyrophosphatase 1 (DCTPP1) is a newly discovered dNTP pyrophosphatase. This study aimed to identify the role of DCTPP1 in oxidative stress and cisplatin response of ovarian cancer. Our results indicates cisplatin-induced ROS generation was responsible for the upregulation of DCTPP1 in ovarian cancer cells, whereas DCTPP1 knockdown significantly enhanced the sensitivity of ovarian cancer cells to cisplatin, reflect in reactive oxygen species (ROS) generation, double-strand DNA breaks, and cell apoptosis. The expression of redox-related genes and the activation of the PI3/Akt signaling pathway were also inhibited by DCTPP1 knockdown. Our data proposes that the development of therapeutic approaches targeting DCTPP1 may be useful in the treatment of ovarian cancer.

Keywords: ovarian cancer, DCTPP1, cisplatin, ROS, cisplatin resistance

\section{INTRODUCTION}

The lack of specific symptoms and early diagnostic markers have made ovarian cancer the most deadly gynecological cancer among women in the world. The current standard treatment for ovarian cancer is surgery accompanied by platinum-based chemotherapy (Brett et al., 2017; Webb and Jordan, 2017). In the past few decades, because of chemotherapy resistance, there has been only a very mild improvement in the survival rate of ovarian cancer patients. Thus, the mechanism of cisplatin resistance needs to be further elucidated to improve the outcome of patients with ovarian cancer (Vlahos et al., 2010; Glubb et al., 2021).

According to reports, cisplatin can induce the ROS-dependent apoptosis in ovarian cancer. ROS is a double-edged sword for tumor development (Fruehauf and Meyskens, 2007; Marullo et al., 2013; Srinivas et al., 2019). High-speed proliferation, resistance to apoptosis, increased migration and invasiveness, several of these features are known to be mediated by reactive oxygen species (ROS). However, oxidative DNA damage caused by ROS might lead to cell senescence or cell death (Han et al., 2019; Kleih et al., 2019; Wang et al., 2020).

Abbreviations: DCTPP1, dCTP pyrophosphatase 1; HO-1, heme oxygenase 1; GCLC, glutamate-cysteine ligase, catalytic subunit; Nrf2NF-E2, related factor 2; qPCR, quantitative PCR; RNAi, RNA interference; ROS, reactive oxygen species; shRNA, short harpin RNA; NTP-PPase, nucleotide triphosphate pyrophosphatase; NAC, N-acetyl-l-cysteine; CD-DST, 3D growth model build by collagen gel droplet culture technology. 
Hence, tumour cells must deal with the oxidative DNA damage of ROS and maintain a suitable high level of ROS at the same time. One way for tumor cells to achieve this purpose is to balance the intracellular ROS levels by increasing the expression of redox protective proteins (Srinivas et al., 2019; Azzouz et al., 2021). Such an adaption would serve to uncouple the tumor-promoting effects of ROS from their tumor-suppressive consequences, and also contribute to the resistance to cytotoxicity of platimuns (Girish et al., 2013; Preya et al., 2017; Li et al., 2019; Rai and Sobol, 2019). The inhibition of redox-protective proteins could significantly sensitize such cells to platinums despite their not having a direct role in cell survival (Girish et al., 2013; Azzouz et al., 2021). As such, identifying the members in this class of proteins is likely to acquisit therapeutic targets with clinically valuable and/or prognostic markers for platinmuns therapy (Rai et al., 2011; Li et al., 2019; Rai and Sobol, 2019).

Detoxification of oxidative damage to DNA precursors is an important downstream mediator of ROS-induced cellular responses (Pecsi et al., 2011; Rai et al., 2011; Lu et al., 2018). Nucleotide triphosphate pyrophosphatase (NTP-PPase) is believed to hydrolyze abnormal nucleotides in cancer cells to maintain genetic stability, so that tumor cells can proliferate and survive under oxidative stress (Pecsi et al., 2011; Rai, 2012; Lu et al., 2018; Martinez-Arribas et al., 2020). dCTP pyrophosphatase 1 (DCTPP1) is a newly discovered dCTP pyrophosphatase with a MAGZ structure. Compared with the NTP-PPase which has been found to hydrolyze dGTP and dUTP and their derivatives, the substrate of DCTPP1 is dCTP, 5-methyl Base-dCTP and 5-halo-dCTPs etc. DCTTP1 exhibits nucleic accumulation in multiple carcinomas (Requena et al., 2014; Requena et al., 2016). Researches have shown that DCTPP1 promotes proliferation of breast cancer via DNA repair signaling pathway (Requena et al., 2016; Xia et al., 2016; Niu et al., 2021). Recently, the regulatory function of DCTPP1 in drug response has gained attraction. DCTPP1 attenuates the sensitivity of human gastric cancer cells to 5-fluorouracil by up-regulating MDR1 expression epigenetically and DCTPP1 is involved in the cellular response to decitabine (Xia et al., 2016; Niu et al., 2021). However, the role of DCTPP1 in response to cisplatin in ovarian cancer cells remains largely unknown.

In the present study, we investigated the role of DCTPP1 in regulating oxidative stress and homeostasis in ovarian caner cells under cisplatin treatment. We show that DCTPP1 amplified antioxidant capacity of OC cells, reflected in reducing oxidative stress-induced DNA damage and cisplatin sensitivity. Our results have provided new insights into potential therapeutic strategies to overcome cisplatin resistance in ovarian cancer.

\section{MATERIALS AND METHODS DCTPP1 Knockdown in Ovarian Cancer Cells}

Human ovarian cancer cell lines SKOV3 and OCAVAR8 were purchased from the cell bank of the Chinese Academy of Sciences (Shanghai, China) and cultured in DMEM culture solution containing $12 \%$ fetal bovine serum, respectively, and placed in an incubator at $5 \% \mathrm{CO} 2,37^{\circ} \mathrm{C}$. Lentivirus contain DCTPP1
shRNA (target:GCCCTTCAAGAGGAGCTTA) and negative controls (5'-GTTCTCCGAACGTGTCACGT-3 $\left.{ }^{\prime}\right)$ were purchased from Shanghai Gima Pharmaceutical Co., Ltd. SKOV3 and OCAVAR8 cells in logarithmic growth phase were planted in 24-well plates with a planting density of $5 \times$ $10^{4}$ /well. When the cell growth density reached $50 \%$, infection was performed for $24 \mathrm{~h}$ according to the instructions and then transected cells are selected by puromycin to establish DCTPP1 knockdown cell. The cells of each group were expanded cultured for follow-up work.

\section{qRT-PCR Analysis}

Ovarian cancer cells were lysed by Trizol method, then total RNA was extracted and synthesized into cDNA.qPCR assay was performed follow the instruction manual of SYBR premix Ex Taq Kit. qPCR reaction program was set to two steps: (a) preincubation at $95^{\circ} \mathrm{C}$ for $30 \mathrm{~s}$; (b) $95^{\circ} \mathrm{C}$ for $5 \mathrm{~s}$ and $55^{\circ} \mathrm{C}$ for $30 \mathrm{~s}$, $72{ }^{\circ} \mathrm{C}$ for $34 \mathrm{~s}$ for 40 cycles. Samples were assayed in triplicate using the ABI Prism 7500 detection system (Applied Biosystems, Foster City, CA, United States). The relative quantization value was then calculated by subtracting the average CT from the corresponding average CT for 18SRNA.

\section{Western Blot Analysis}

Cells were harvested and lysed in ice-cold lysis buffer $(10 \mathrm{mM}$ Hepes, pH 7.9; $150 \mathrm{mM} \mathrm{NaCl} ; 1 \mathrm{mM}$ EDTA); The protein concentration of cell Lysate was determined by BCA protein assay kit. Samples were separated by $10 \%$ or $12 \%$ sodium dodecyl sulfate polyacrylamide gel electrophoresis (SDS-PAGE) and transferred to polyvinylidene difluoride (PVDF) membranes (Millipore,United States), which was then blocked in 5\% BSA blocking buffer at $4^{\circ} \mathrm{C}$ overnight. All antibodies (dilution, 1:1,000; Santa Cruz Biotechnology, Santa Cruz, CA, United States) were incubated on shaking bed overnight at $4^{\circ} \mathrm{C}$ respectively. Secondary antibody was incubated at room temperature for 30 min.Densitometric quantification of protein bands were visualized using ECL-Plus detection reagents (Santa Cruz Biotechnology, Santa Cruz, CA, United States) and performed with GAPDH as an internal control using ImageJ.

\section{Luciferase Reporter Assay}

The genomic DNA was routinely extracted according to the instructions of the genome extraction kit. Two different promoter sequences of DCTPP1 (P1: 2000 -0 bp upstream of DCTPP1 coding sequence; P2:674-0 bp upstream of DCTPP1 coding sequence) were cloned and inserted into the luciferase vector. The luciferase reporter plasmids named luc-2000 and luc674 respectively, were transfected into cells with empty vector as a control. The Dual luciferase reporter assay kit (promega, Madison, Wisconsin, United States) was used to detected the luciferase signal.

\section{Cell Viability Assay in vitro (CCK-8)}

Cells $\left(1 \times 10^{3} / 100 \mu \mathrm{L}\right)$ were seeded in 96-well plates (Corning, New York, United States) and cell viability was analyzed by using CCK-8 kit (Dojindo Laboratories, Kumamoto, Japan) according to the manufacturer's instructions. The absorbance of $450 \mathrm{~nm}$ 
was measured on a microplate reader (BioRad, CA, United States) and the cell growth curves were calculated.

\section{Flow Cytometry for Apoptosis Analysis}

Cells $\left(1 \times 10^{5}\right)$ were Collected for cell apoptosis assay using propidium iodide (PI, Sigma, Shanghai, China) and apoptosis assay using FITC-Annexin V Apoptosis Detection Kit (Biolegend, San Diego, CA, United States) according to the manufacturer's instructions. Stained Cells $(10,000$ events for each sample) were acquired by FACS (BD Pharmingen, San Diego, CA, United States) and the results were analyzed with MLFT32 software.

\section{Rreactive Oxygen Species Level Detection}

ROS levels were detected using dihydroethidium (DHE) (SigmaAldrich, CA, United States). Cells were harvested and incubated with DHE $(10 \mu \mathrm{M})$ for $10 \mathrm{~min}$ at $37^{\circ} \mathrm{C}$ in the dark. Relative red fluorescence was measured using a flow cytometer (BD Pharmingen,CA, United States).

\section{D Growth Model Build by Collagen Gel Droplet Culture Technology (CD-DST)}

Briefly, type I collagen (Cellmatrix Type CD; Nitta Gelatin, Inc., Osaka, Japan), 10× F-12 medium, and reconstitution buffer were mixed together at a ratio of 8:1:1. The prepared tumor cells and collagen solution are inoculated at a volume ratio of 10:1, so that the final density of cells in the collagen droplets is $2 \times 10^{5}-5 \times 10^{5}$ pieces $/ \mathrm{mL}$. The collagen-cell mixture $(30 \mu \mathrm{L} / \mathrm{drop})$ was transferred to the 6-well multiplate and cultured at $37^{\circ} \mathrm{C}$ in a $\mathrm{CO}_{2}$ incubator. After culture for 16 days, Each collagen droplet was stained with neutral red, fixed with $10 \%$ neutral formalin buffer, washed with water, and quantified by culture cell analysis system. Image analysis at $540 \mathrm{~nm}$ would quantify the number of DCTPP1 knockdown cells and control cells.

\section{Immunohistochemistry}

Ovarian cancer specimens are surgical resection specimens, the specimens are fixed with $10 \%$ neutral formaldehyde after removal from the body. Immunohistochemistry was done using $8 \mu \mathrm{m}$ serial sections placed onto glass slides using a single-staining procedure.

The protocols used with DCTPP1 and Ki67 antibody (dilution, 1:50; Santa Cruz Biotechnology, Santa Cruz, CA, United States) are carried out according to the instructions of Immunohistochemistry kit, and negative and positive controls were seted. Double-blind reading method was used to judge the staining results: two experienced doctors read the pictures separately, 10 representative fields were randomly observed in each slice, and comprehensive analysis and scoring was performed according to the respective staining degree and number of stained cells.

\section{Comet Assay}

Alkaline unwinding and electrophoresis conditions was carried out according to instructions for the comet assay kit (Phgene, KM,China). A minimum of 100 individual cells per sample were scored in duplicate from three independent experiments. According to the DNA tail lengths, cell damage is divided into three levels: level 1, none (no damage); level 2, medium (moderate damage); level 3, long (severe damage);

\section{Statistical Analysis}

Graphpad prism 5.0 and Excel 2016 was used to generate the graphs and process the data. The significance was analyzed with the unpaired $\mathrm{t}$-test and one-way ANOVA, $p$ values $<0.05$ were considered significant. Data were expressed as the mean \pm SD from at least three independent experiments.

\section{RESULT}

\section{Overexpression of DCTPP1 is a Poor Prognostic Marker in Ovarian Cancer}

Immunohistochemistry was used to measure DCTPP1 protein expression, represented by immunoreactivity score (IRS) in OC tissues and adjacent non-cancerous fallopian tubes tissues. As shown in Figure 1A, Expression of DCTPP1 was weakly or almost no stained in non-cancerous fallopian tubes tissues, positive signals of DCTPP1 was detectable mainly in the nucleus and cytoplasm of cancerous tissues. Statistical analyses indicated that DCTPP1 expressions in OC tissues of III and IV stage are significantly higher than that inadjacent non-cancerous fallopian tubes tissues with $p<0.05$ (Figure 1B).

Correlation between DCTPP1 expression and clinicopathological parameters was further analyzed, the expression of DCTPP1 was higher in older patients $(>56$ years old), no evident correlations were observed between DCTPP1 expression with the FIGO stage, lymph node and omentum metastasis, and CA125 (Table 1). The correlation between DCTPP1 expression and disease prognosis was analysis using the Kaplan-Meier assay. As shown in Figure 1C, 887 patients in the DCTPP1-high group exhibited a poorer prognosis when compared with 768 patients in the DCTPP1-low group ( $p=$ 0.022 , Figure 1C). These results indicate that DCTPP1 is strongly associated with ovarian cancer prognosis and might play some role in ovarian cancer progression. And under the condition of cisplatin treatment, there was significant difference in the overall survival ( $p=0.0034$ ) between the patients in DCTPP1-high group and the patients in DCTPP1-low group. This results suggested that patients with high expression of DCTPP1 had a poor response to cisplatin treatment (Figure 1D).

\section{DCTPP1 Expression Could be Induced by Cisplatin Through ROS Generation}

In order to determine the role of ROS in cisplatin-induced cytotoxicity, we tested the level of ROS generation in the two ovarian cancer cells after cisplatin treatment. The results showed that cisplatin increased ROS levels and correspondingly increased apoptosis ratio in SKOV3 and OVCAR8 cells (Figures 2A,B), while cisplatin-induced apoptosis decreased when $\mathrm{N}$-acetyl-1cysteine (NAC) was added (Figure 2C). These results suggest cisplatin-induced generation of reactive oxygen species (ROS) has 

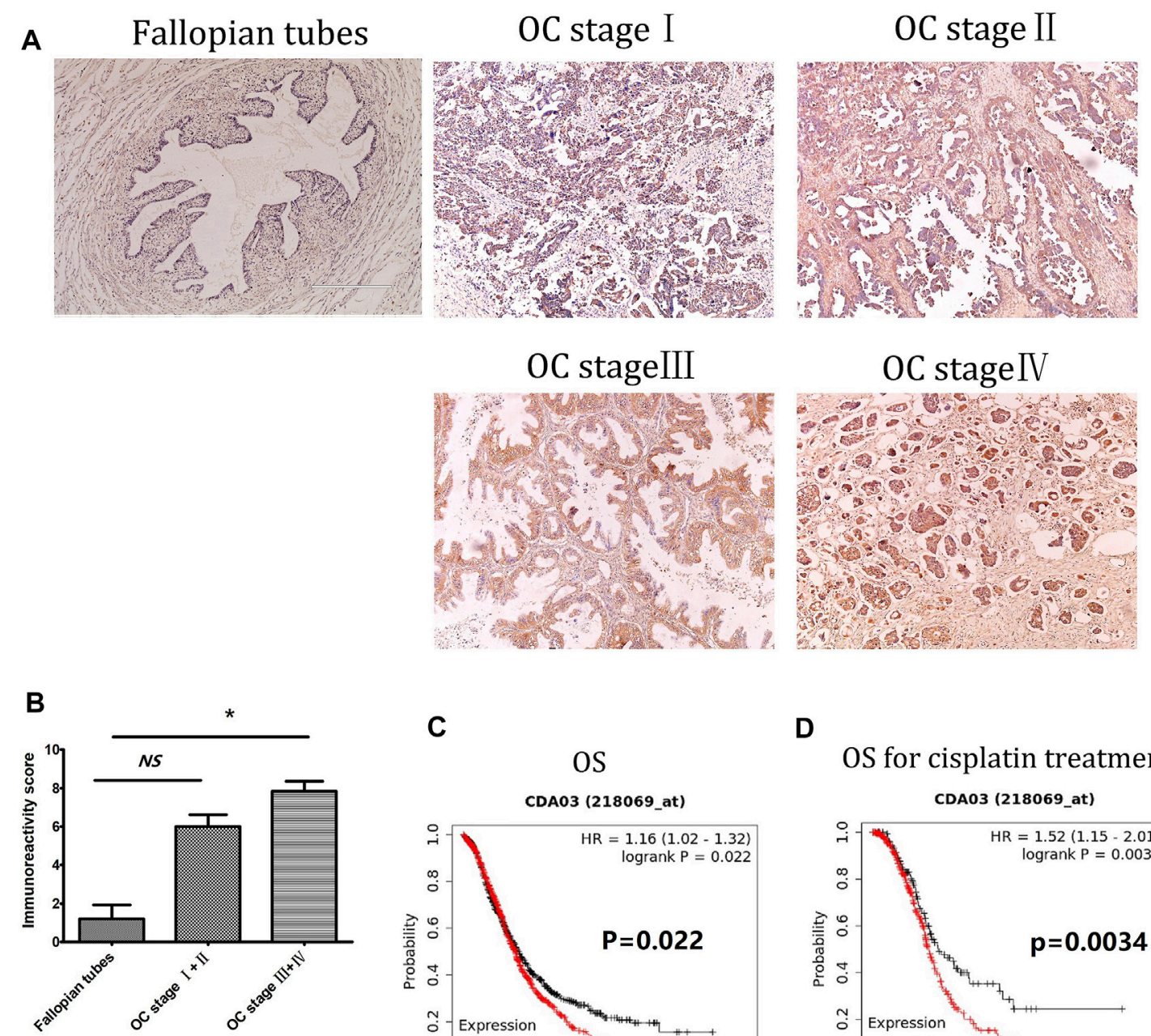

C

OS

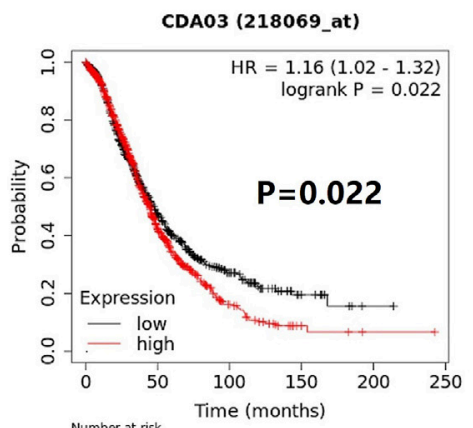

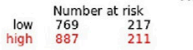

FIGURE 1 | Overexpression of DCTPP1 is a poor prognostic marker in ovarian cancer. (A) Immunohistochemistry staining of DCTPP1 on human Fallopian tubes and ovarian cancer tissues. (B) Scoring of DCTPP1 staining in human ovarian cancer tissues with different pathological grade (Fallopian tubes, stage I + II, stage III + IV). ${ }^{*}, p<0.05$; ns, no significance. (C) Kaplan-Meier analysis of overall survival (OS) in ovarian cancer patients based on DCTPP1 expression level. (D) Kaplan-Meier analysis of overall survival (OS) in ovarian cancer patients with cisplatin treatment based on DCTPP1 expression level.

TABLE1 | Correlation between DCTPP1 expression and clinicopathological characteristics.

\section{Clinicopathological features}

$\begin{array}{lr} & \\ \text { Age (years) } & <56 \\ & \geq 56 \\ \text { FIGO staging } & I+I I \\ & I I I+I V \\ \text { CA125(U/ml) } & <600 \\ & \geq 600 \\ \text { Lymph node metastasis } & \text { positive } \\ & \text { nagetive } \\ \text { Transcoelomic Metastasis } & \text { positive } \\ & \text { nagetive }\end{array}$

\section{DCTPP1 expression}

Low expression

High expression

\section{$p$ Value}

$0.0060^{*}$

0.75

0.47

0.06

0.58

${ }^{*} P<0.05$, compared to the low expression group. 

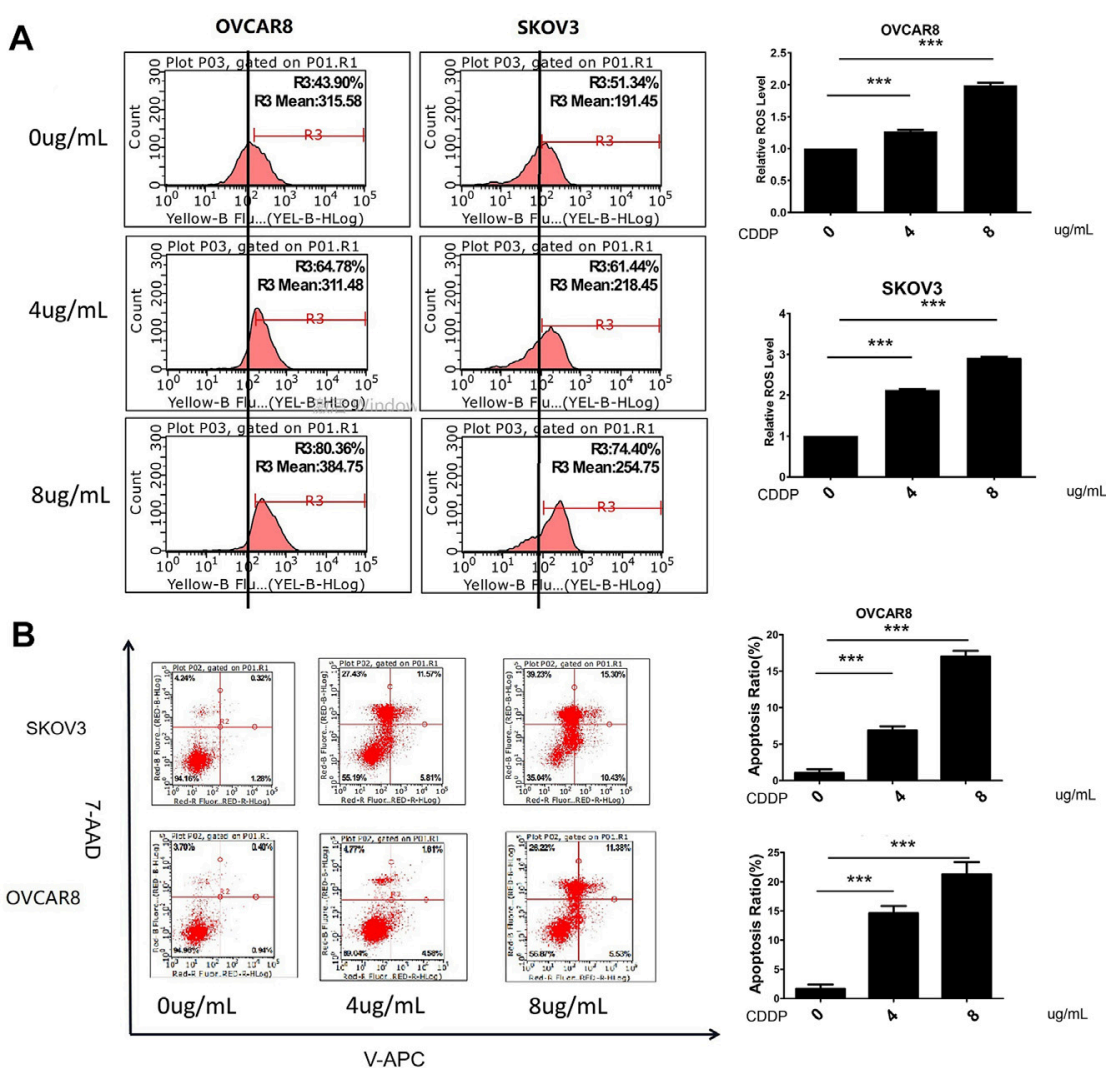

C

OVCAR8

SKOV3
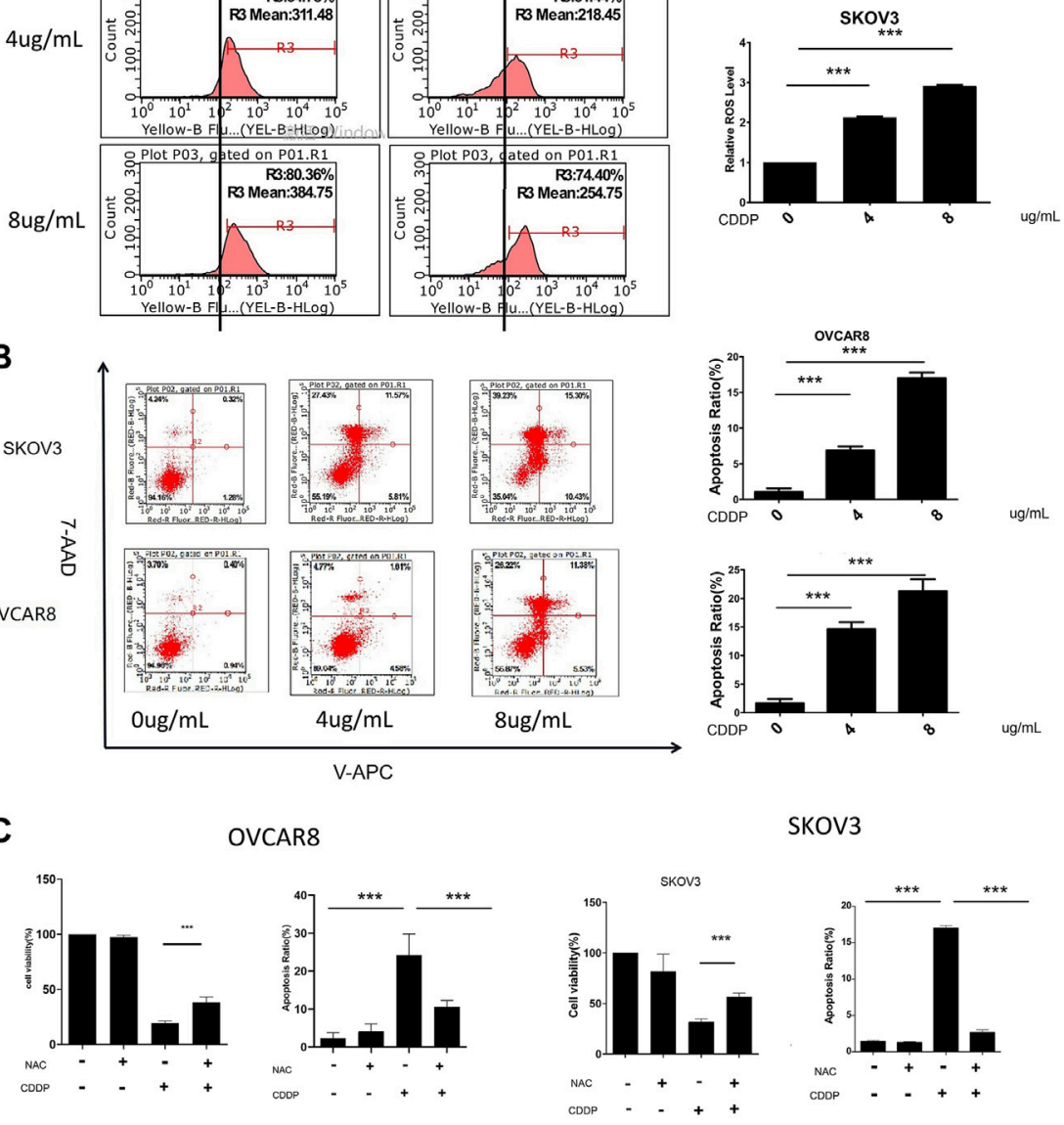

D
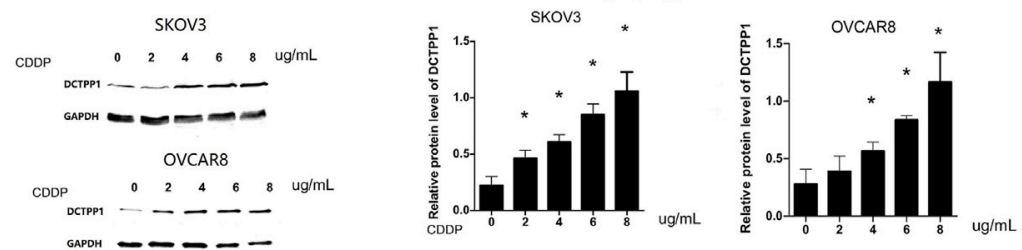

E
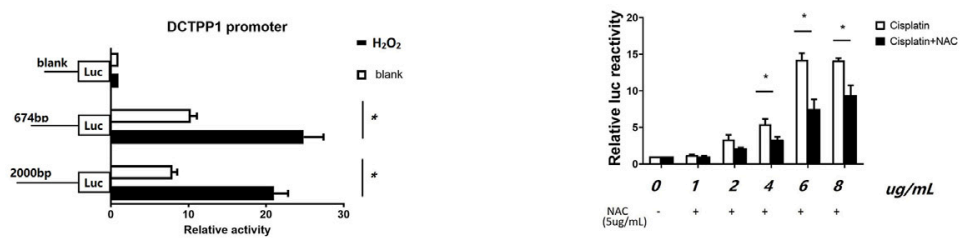

FIGURE 2 |DCTPP1 expression could be induced by cisplatin through ROS generation. (A) The level of reactive oxygen species (ROS) was detected using DHE in OVCAR8 and SKOV3 cells treated with different concertration cisplatin $(0,4$, and $8 \mu \mathrm{g} / \mathrm{ml})$; ${ }^{\star \star \star}, p<0.001$; B. Cell apoptosis ratio was analyzed with flow cytometry in OVCAR8 and SKOV3 cells treated with different concertration cisplatin $(0,4,8 \mu \mathrm{g} / \mathrm{ml}) ;{ }^{* * *}, p<0.001$; (C) Statistical analysis of cell viability and apoptosis ratio exposed to cisplatin $(4 \mathrm{\mu g} / \mathrm{ml})$ with or without NAC $(5 \mu \mathrm{g} / \mathrm{ml}) .{ }^{*} p<0.05 ;{ }^{* \star}, p<0.01 ;{ }^{\star \star *}, p<0.001$; (D) Western blot analysis of SKOV3 and OVCAR8 cells treated with cisplatin $(0,2,4,6,8 \mathrm{\mu g} / \mathrm{ml}) .{ }^{*} p<0.05 ;{ }^{* \star}, p<0.01 ;{ }^{\star \star \star}, p<0.001 ;$ (E) luciferase reporter assay analysis of DCTPP1 promoter luciferase reporters in SKOV3 cells treated with different concertration cisplatin $(1,2,4,6$, and $8 \mu \mathrm{g} / \mathrm{ml})$ and $\mathrm{NAC}(5 \mu \mathrm{g} / \mathrm{ml}),{ }^{*} p<0.05$. 


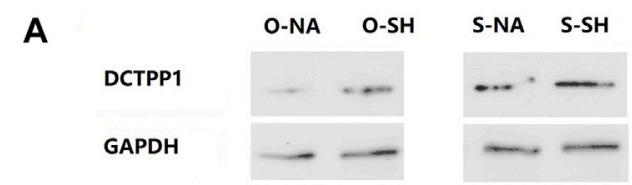

B
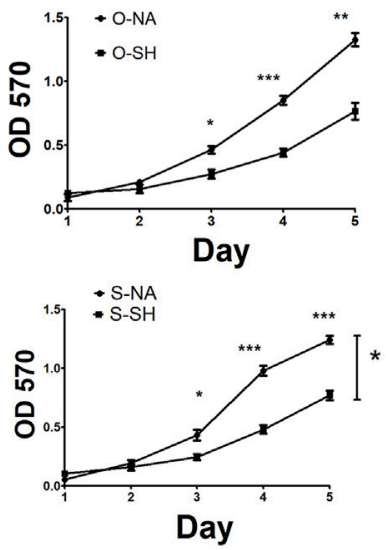

C

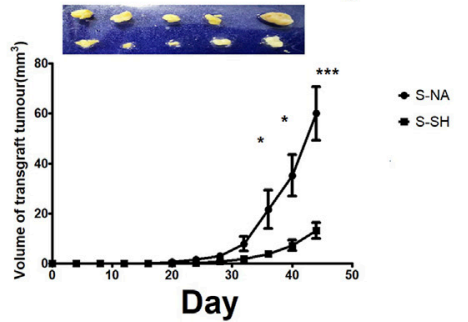

D

D S-NA
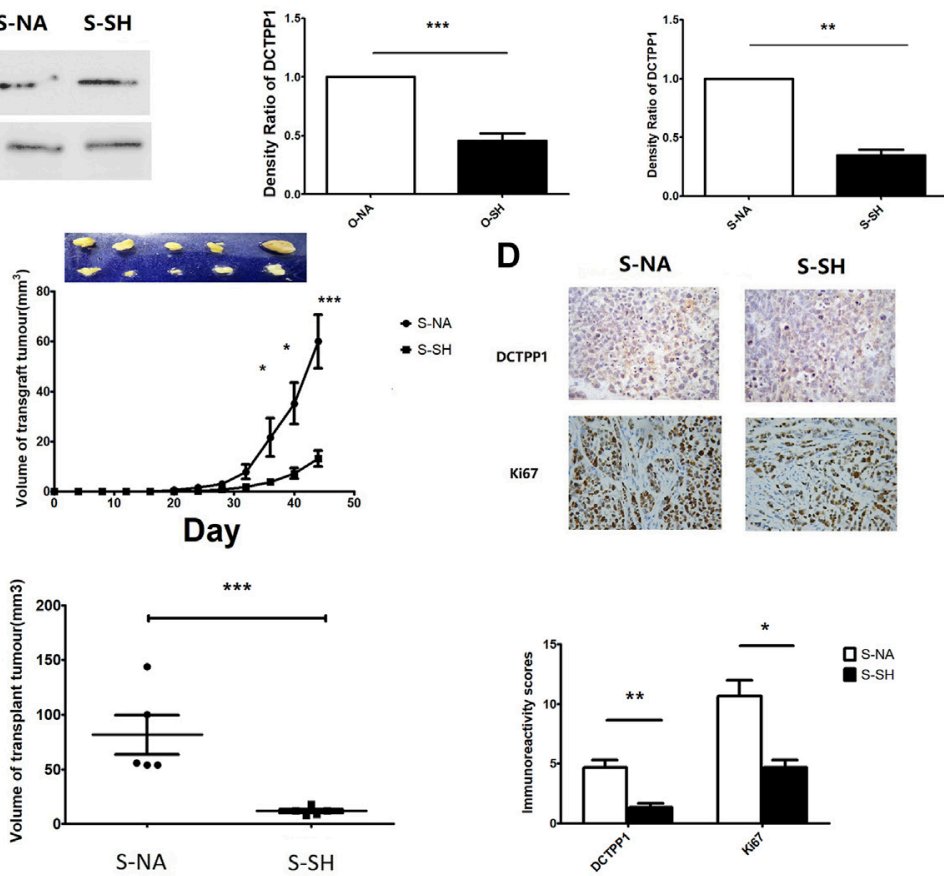

$\mathbf{E}$
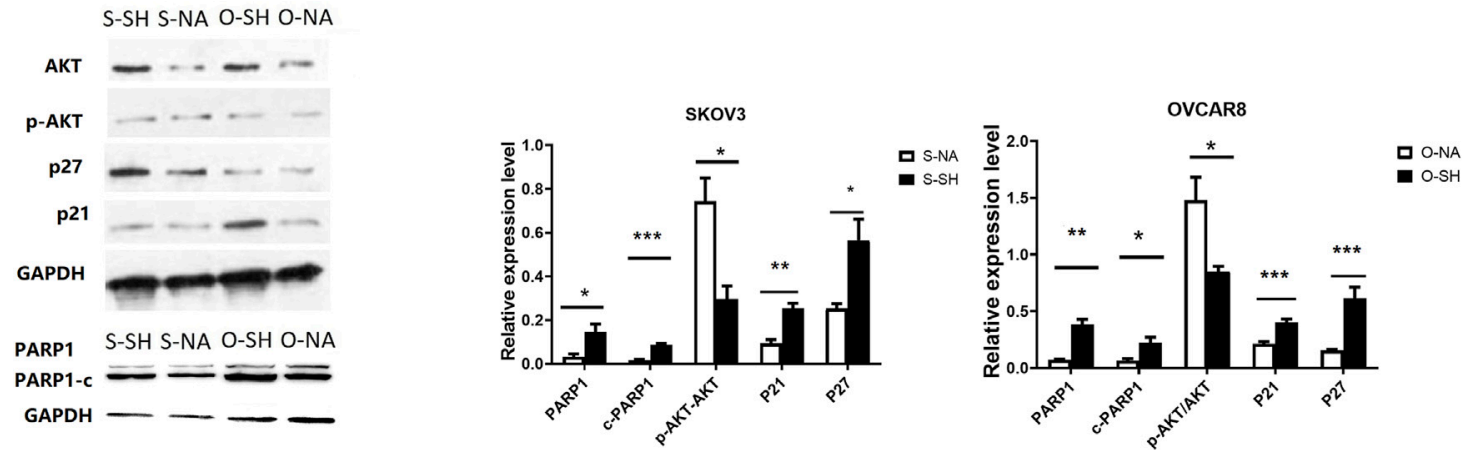

FIGURE 3 | Knockdown of DCTPP1 inhibits tumor growth via regulating the Akt pathway. (A) Western blot analysis and densitometric quantification of DCTPP1 in SKOV3 and OVCAR8 cells treated with shRNA against DCTPP1. ${ }^{* *}, p<0.01 ;{ }^{* \star}, p<0.001$; (B) Growth curve of SKOV3 and OVCAR8 cells with the indicated shRNA transpected. ${ }^{*} p<0.05 ;{ }^{\star \star}, p<0.01 ;{ }^{\star \star \star}, p<0.001$; (C) Up:Mean tumor growth curves for xenografts from SKOV3 cells transfected with shRNA and the control respectively. ${ }^{*} p<0.05,{ }^{* \star *}, p<0.001$; compared to S-NA; Down: Mean tumor volume of xenografts from SKOV3 cells transfected with shRNA and the control respectively at 6 weeks ${ }^{\star \star \star}, p<0.001$; (D). DCTPP1 and Ki67 immunohistochemistry in SKOV3 cells transfected with shRNA and the control respectively; ${ }^{*} p<0.05 ;{ }^{* *}, p<$ 0.01; (E) Western blot analysis and densitometric quantification of P21,P27,PARP1,c-PARP1,Akt,p-Akt in ovarian cancer cells transfected with shRNA and the control respectively. Data are presented as mean $\pm \mathrm{SEM} .{ }^{*} p<0.05 ;{ }^{* \star}, p<0.01 ;{ }^{\star \star *}, p<0.001$

been correlated to its cytotoxic effects, which makes specific ROS scavengers being great significance to cisplatin resistance.

As shown in Figure 2D, induction effect of cisplatin on DCTPP1 was observed in both SKOV3 and OVCAR8 cells at the protein level after cisplatin treatment $(p<0.05)$. These results suggest that DCTPP1 might be a response factor for cisplatin. And then, we investigated our hypothesis that DCTPP1 expression could be induced by cisplatin through ROS generation. The dual luciferase reporter gene system is used to efficiently detect the transcriptional activation of DCTPP1. As shown in Figure 2E, the DCTPP1 promoter can be activated by the ROS inducer $\mathrm{H}_{2} \mathrm{O}_{2}(500 \mathrm{uM})$, suggesting that DCTPP1 is a response factor of oxidative stress. At the same time, the activation of the DCTPP1 promoter by cisplatin can be reversed by N-acetyl-l-cysteine (NAC), the oxidative stress inhibitor $(p<0.05$, Figure 2E). These results show that intracellular ROS accumulation induced by cisplatin up-regulated the transcription of DCTPP1. In summary, DCTPP1 expression could be induced by cisplatin through ROS generation.

\section{Knockdown of DCTPP1 Inhibits Tumor Growth via Regulating the Akt Pathway}

Figure 3A shows cell lines with stable DCTPP1 knockdown were constructed, and the knockdown efficiency was assessed by 


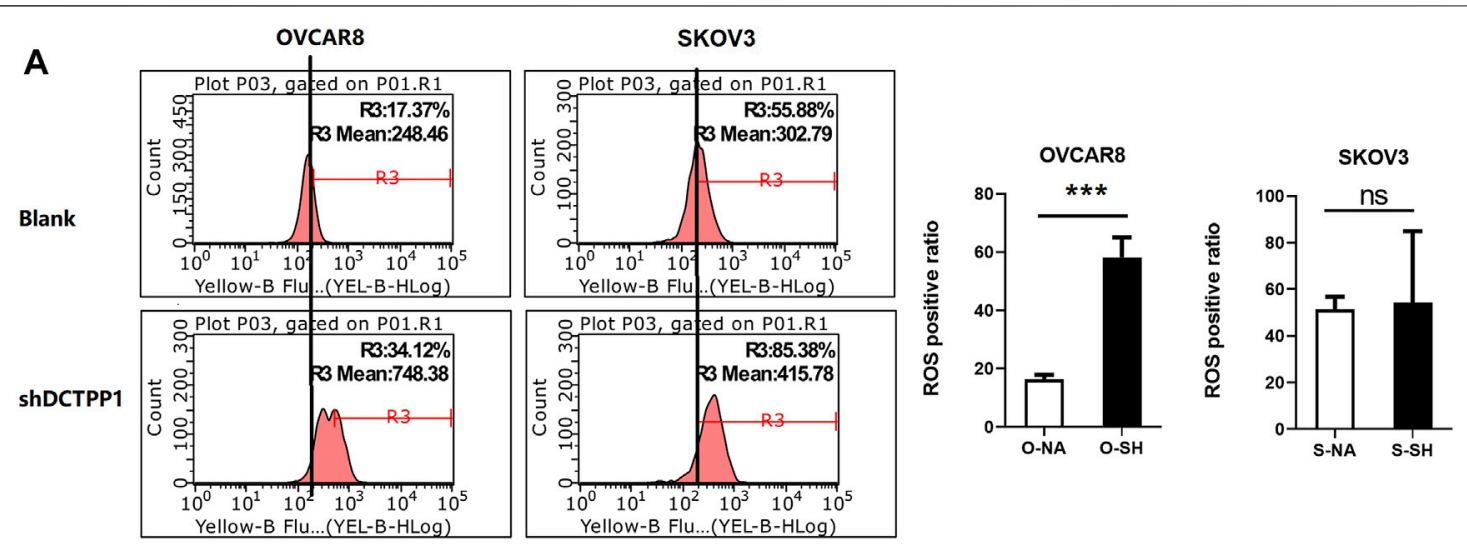

B

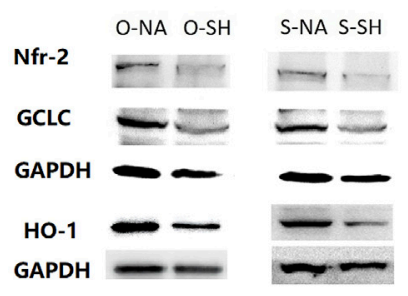

C
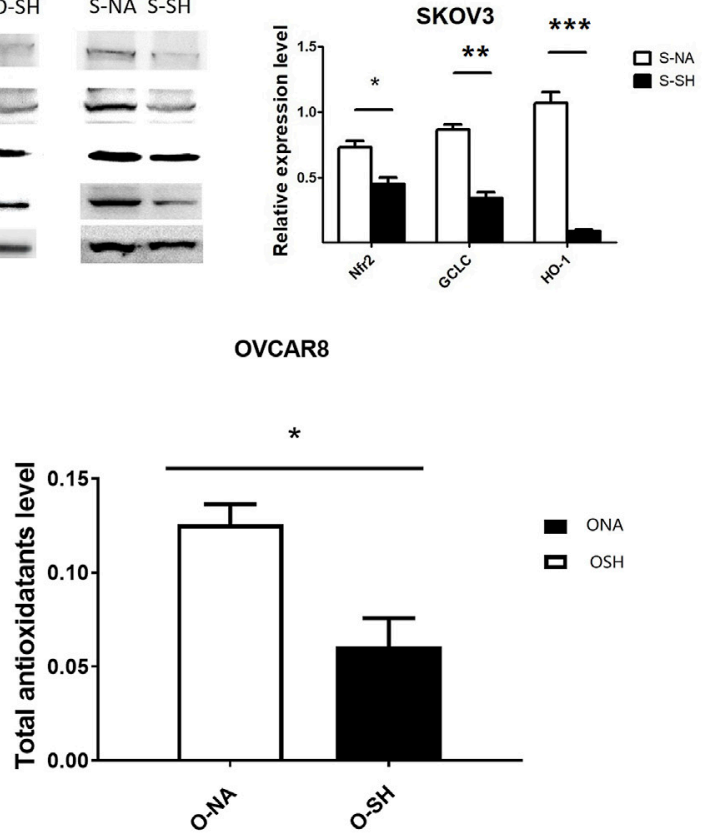
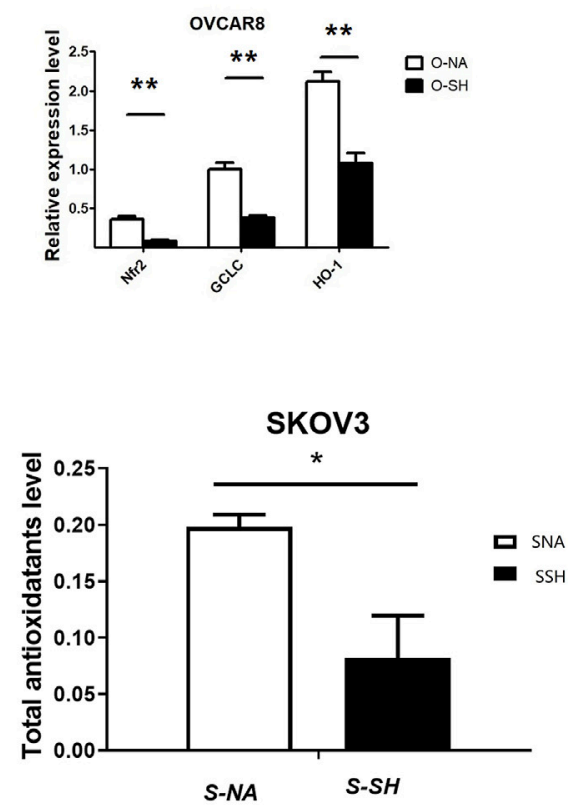

FIGURE 4 | DCTPP1 knockdown induces ROS overproduction in ovarian cancer cells. (A) The level of reactive oxygen species (ROS) was detected using DHE in control or DCTPP1 knockdown cells. ${ }^{\star \star *}, p<0.001$; ns, no significance. (B) Western blot analysis and densitometric quantification of Nrf2, GCLC and HO-1in ovarian cancer cells transfected with shRNA and the control respectively. Data are presented as mean $\pm \mathrm{SEM} .{ }^{\star} p<0.05 ;{ }^{\star \star}, p<0.01 ;{ }^{\star \star \star \star}, p<0.001 ;$ (C) Total antioxidotatants level of ovarian cancer cells transfected with shRNA and the control respectively. Data are presented as mean \pm SEM.* $p<0.05$.

Western blot respectively $(p<0.05)$. The OVCAR8 and SKOV3 cell lines with stable knockdown of endogenous DCTPP1 by short hairpin RNA (shRNA) were named as S-SH and O-SH respectively, the control cell lines were named $\mathrm{S}-\mathrm{NA}$ and O-NA respectively. These four cell lines were selected for use in subsequent experiments.

CCK-8 assay were conducted to determine the cell growth. As shown in Figure 3B, the growth curves indicated that the growth rate was significantly lower in DCTPP1 knockdown cells than the control cells. A xenograft tumor mouse model was established to identify the impact of DCTPP1 on tumour growth in vivo. As shown in Figure 3C, loss of DCTPP1 expression resulted in a significant delay in tumor growth, where the difference in tumor volume was statistically significant after 6 weeks $(p<0.05)$. Ki67, a marker of tumour proliferation, was also observed to be decreased in DCTPP1 knockdown groups by immunohistochemistry (Figure 3D). As mounting evidence indicates that PIK3/ Akt pathway always plays a crucial role in tumour growth, DCTPP1 deletion in both SKOV3 and OVCAR8 cells resulted in an elevated level of p21 and, at the same time, a decreased level of pAkt/Akt (Figure 3E). These results might predict the DCTPP1 knockdown would sensitize the sensitivity of cisplatin of ovarian cancer cells. Correspondingly, we have also observed an increase in the expression of apoptosisrelated proteins PARP1 and c-PARP1, which suggested that the knockdown of DCTPP1 may stimulate cell apoptosis by down-regulating the activation of the Akt pathway. 

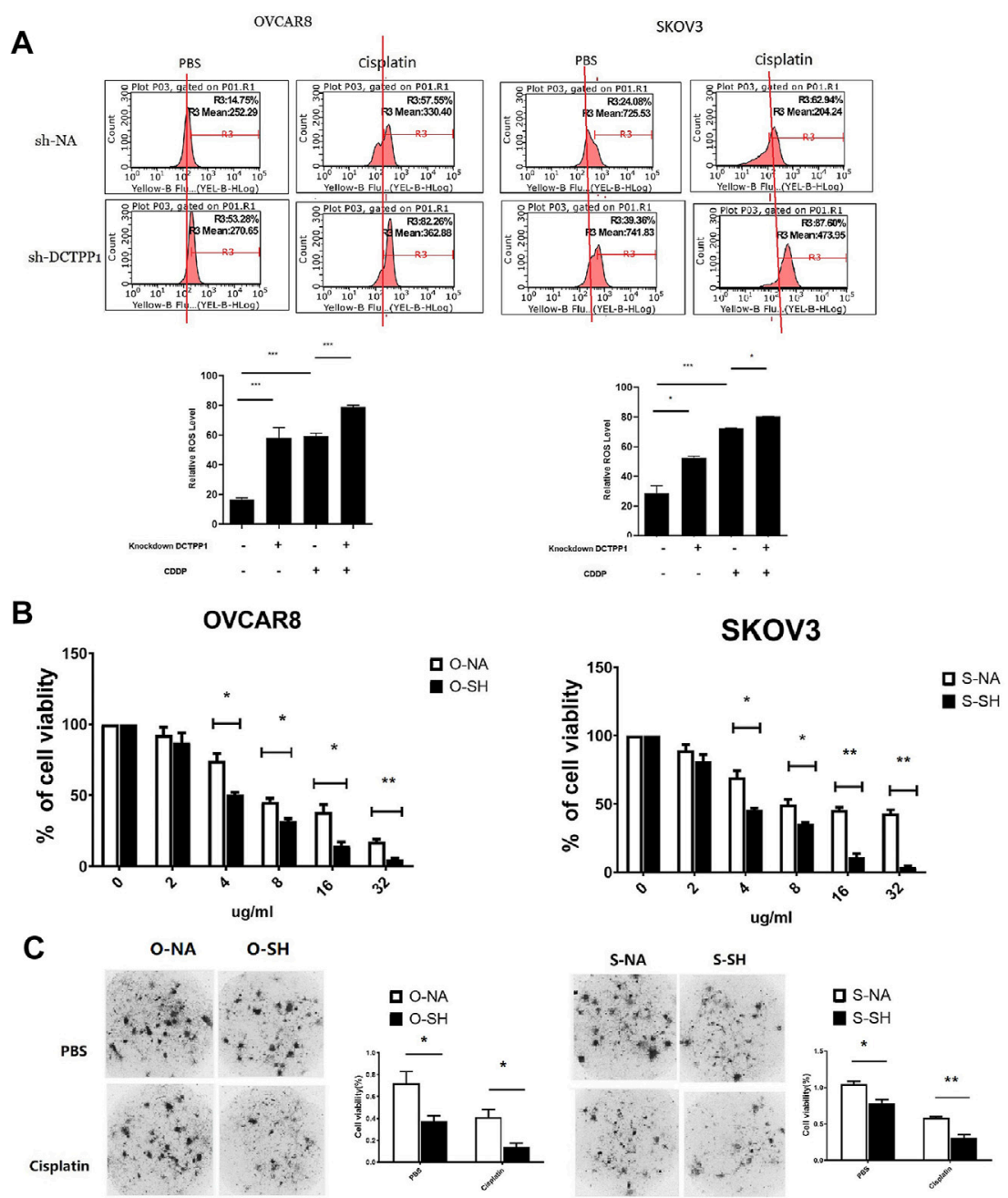

D
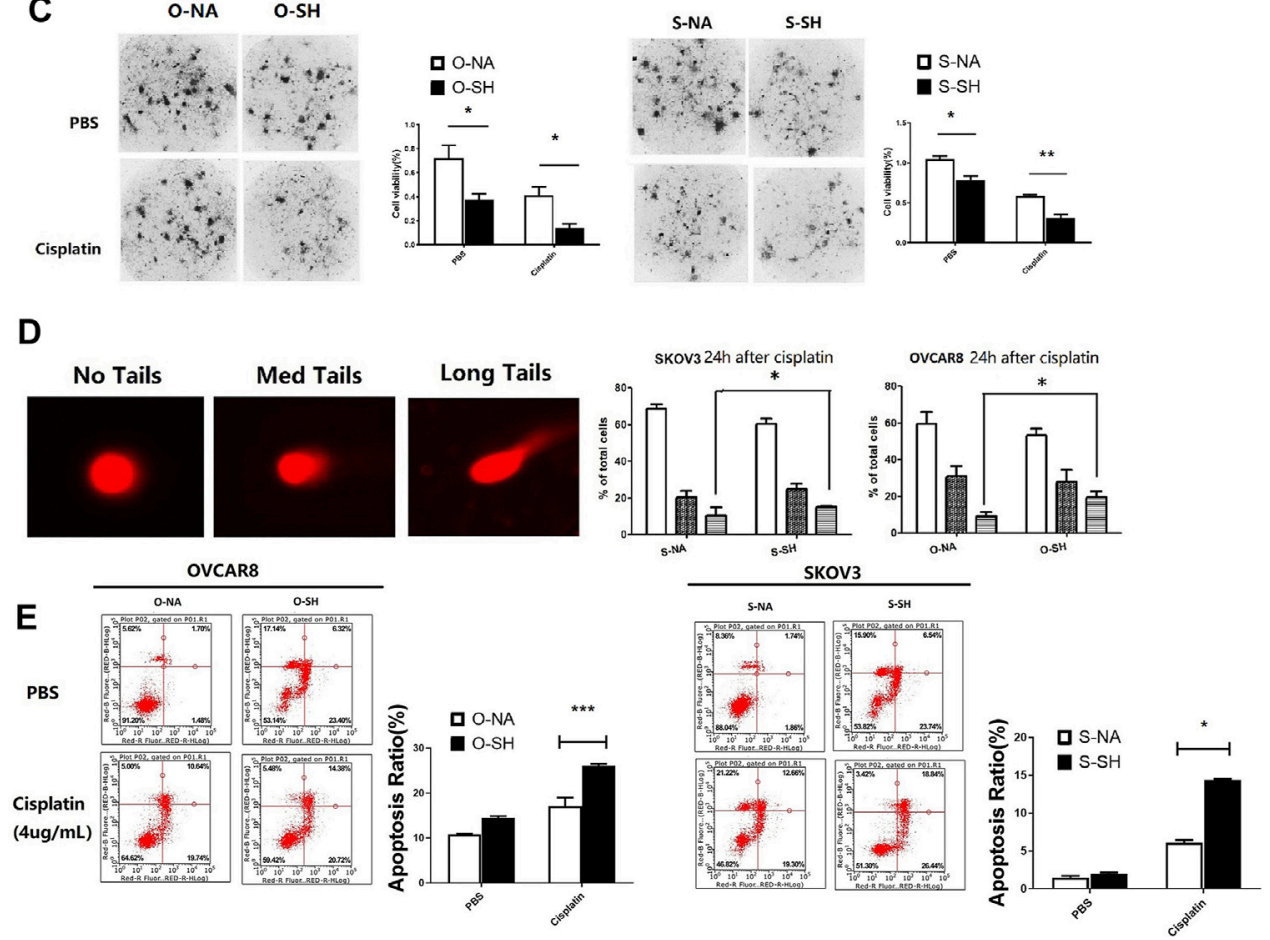

FIGURE 5 | DCTPP1 knockdown increases cisplatin-sencitivity in cisplatin-sensitive ovarian cancer cells. (A) The level of reactive oxygen species (ROS) was detected using DHE in control or DCTPP1 knockdown cells treated or without treated with cipalin $(4 \mu \mathrm{g} / \mathrm{ml}) .{ }^{*} p<0.05 ;{ }^{\star \star \star}, p<0.001$. (B) DCTPP1 knockdown inhibit cell viability both in SKOV3 and OVCAR8 cells treated with cisplatin of different concentration (0, 2, 4, 8, 16, and $32 \mu \mathrm{g} / \mathrm{ml})$. * $p<0.05$; ${ }^{* *}, p<0.01$; (C) Clone-formation of ovarian cancer cells infected with lentiviral DCTPP1 shRNA and a control shRNA, was measured by the CD-DST assay. ${ }^{*}, p<0.05 ;{ }^{* *}, p<0.01$. (D) Alkaline comet assay data is shown the indicated samples. Representative single cell images used for scoring within the three categories are shown next to the quantitation. ${ }^{*} p<0.05$. (E) Apoptosis was analyzed by flow cytometry. Representative plots showing the redistribution of phosphatidylserine (annexin $V$ staining) in the presence of propidium iodide (PI). Statistical analysis of apoptosis of cells exposed to PBS and cisplatin, respectively. ${ }^{*} p<0.05 ;{ }^{* \star}, p<0.001$. 


\section{DCTPP1 Knockdown Induces ROS Overproduction in Ovarian Cancer Cells Under Cisplatin Treatment}

Cisplatin is a well-known inducer of ROS and our previous researches have demonstrated that the cytotoxic effect of cisplatin was related to the increasing intracellular ROS level. We hypothesized that DCTPP1 promotes resistance of ovarian cancer cells to cisplatin-induced intracellular ROS production. To reveal the effect of DCTPP1 knockdown on intracellular ROS generation, we detected the total ROS levels in ovarian cancer cells using DHE staining. Although the effect of DCTPP1 knockdown on the level of intracellular ROS is not obvious, it has certain statistical significance (Figure 4A, $p<0.05$ ) in OVACAR8 cells. It is worth noting that we have observed a significant downregulation of Nrf2 after DCTPP1 knockdown (Figure 4B, $p<0.05$ ). More importantly, DCTPP1 knockdown also led to a decrease in glutamate-cysteine ligase, catalytic subunit (GCLC) and heme oxygenase 1 (HO-1), two of the major antioxidants located downstream of Nrf2 to suppress oxidative stress (Figure 4B, $p<0.05$ ). These results suggest that overexpression of DCTPP1 in ovarian caner might activate the Nrf2-dependent antioxidative response in ovarian cancer cells, thus avoiding the oxidative stress and maintaining survival. Correspondingly, we observed changes in the total antioxidant capacity in the cells. DCTPP1 knockdown reduced the total antioxidant capacity (Figure $4 \mathrm{C}, p<0.05$ ), which further proved that DCTPP1 can participate in the redox homeostasis of the cell by regulating the Nrf-2-dependent antioxidant response.

\section{DCTPP1 Knockdown Increases Cisplatin-Sencitivity in Cisplatin-Sensitive Ovarian Cancer Cells}

To determine whether there was a causal link between cisplatininduced upregulation of DCTPP1 and cisplatin-sensitivity, we observed the intracellar ROS in DCTPP1 knockdown cells under cisplatin treatment compare to the control. Compared to their parental cell lines, significantly higher intracellular ROS concentrations were detected after DCTPP1 knockdown, which indicated that DCTPP1 knockdown significantly increases intracellular ROS levels in ovarian caner cells cotreated with cisplatin $(p<0.05$, Figure 5A). These results verified our hypothesis that the high expression of DCTPP1 may rebalance the excessive accumulation of ROS induced by cisplatin treatment. DCTPP1 knockdown might cause more oxidative stress in ovarian cancer cells under cisplatin treatment. The viability of SKOV3 and OVCAR8 cells exposed to cisplatin with or without DCTPP1 knockdown were assessed by CCK-8 assay and CD-DST assay. There is significant difference in cell viability between DCTPP1 knockdown group and the control group both in CCK-8 assay ( $p<0.05$, Figure 5B) and CD-DST assay ( $p<0.05$, Figure 5C). Both assays showed that DCTPP1 knockdown inhanced cisplatin sensitivity of ovarian cancer cells in both OVCAR8 and SKOV3 cells. Given that the main biological function of DCTPP1 is to maintain the safety of nucleic acids, comet assay was used to access the occurrence of double-strand DNA breaks (DSB), which is a natural progression of oxidative DNA damage lesions. Figure 5D shows that DCTPP1 knockdown lead to more long-tail cells in SKOV3 and OVCAR8 cells, which represent an increasing of DSB $(p<0.05)$. Then, we stained cells with Annexin V/PI following exposure to cisplatin with or without DCTPP1 knockdown, and Figure 5E shows that cisplatin-induced apoptosis was increased by DCTPP1 knockdown both in SKOV3 and OVCAR8 cells $(p<$ 0.05 ). These results suggest that cisplatin-induced upregulation of DCTPP1 may be one of the mechanisms by which ovarian cancer resists the cytotoxicity of cisplatin. DCTPP1 knockdwon might enhence the cisplatin sensitivity of ovarian cancer cells and might be a promising therapeutic strategy.

\section{DISCUSSION}

DCTPP1, identified as a nucleoside triphosphate pyrophosphohydrolases, plays a critical role in the DNA repair mechanisms by eliminating harmful dCTP after DNA synthesis for the stabilization of dNTP pools and preventing oxidative damage of nDNA (16-20). In present study, we found protein expression level of DCTPP1 was significantly higher in OC tissues than in non-cancerous tissues and is associated with poor prognosis. More notably, patients with high expression of DCTPP1 showed a worse prognosis under cisplatin treatment. These results all show that DCTPP1 has the predictive potential for the ovarian cancer prognosis and chemotherapy efficacy.

In view of the powerful nucleic acid damage ability of ROS, cancer cells must prevent the accumulation of ROS to ensure the normal physiological metabolism (8-11). In this study, we verified that oxidative damage induced by cisplatin is the main factor of cytotoxicity, and then observed that cisplatin upregulates the expression of DCTPP1 by generating ROS in ovarian cancer cells. These finding virified our speculation that the high expression of DCTPP1 may be in response to the intracellular ROS accumulation induced by cisplatin. These results give us confidence to further verify the role of DCTPP1 in cisplatin resistance.

First, we used lentivirus to deliver shRNA targeting DCTPP1 to construct the DCTPPI knockdown cell model of ovarian cancer cells. Through the cell models, we have observed that DCTPP1 is a promoter for the growth of ovarian cancer, which is consistent with the finding in prostate cancer and gastric cancer (Marquard and Jucker, 2020; Niu et al., 2021). With DCTPP1 knockdown, ovarian cancer cells showed growth inhibition both in vivo and in vitro. DCTPP1 inhibition also appears to have a negative impact on the survival and tumor malignancy of cancer cells. Our results show that DCTPP1 inhibition triggers a significant reduction in Akt activation (measured by the score of phosphorylated Akt/total Akt), and an ehancement in p21, p27 and PARP1 expression. As shown in previous studies, the activation of Akt signaling pathway and the inactivation of P21 are one of the reasons for the failure of chemotherapy, which further suggests the possibility that DCTPP1 might be involved in cisplatin resistance. 
Under normal circumstances, the activation of PI3K/Akt pathway in tumor cells can trigger the increase of intracellular ROS and promote tumor malignant transformation, but ROS overload can reverse the activation of PI3K/Akt pathway through the expression of PTEN (Jaramillo and Zhang, 2013; Jang et al., 2016; Wu et al., 2020). Therefore, We verified whether the decrease in phosphorylated Akt levels observed during DCTPP1 inhibition due to some feedback mechanism in response to an increased ROS accumulation induced by shDCTPP1. While, the responses of the two ovarian cancer cells were inconsistent after knockdown of DCTPP1. OVCAR8 showed a significant increase in intracellular ROS, but SKOV3 showed no significant difference. Therefore, we cannot be sure that DCTPP1 knockdown can directly increase the level of intracellar ROS in ovarian cancer cells.

We further observed the relationship between DCTPP1 knockdown and intracellar redox homeostasis. DCTPP1 knockdown markedly decreased protein levels of Nrf2, GCLC, and HO-1 in both two cells. Nrf2 is a key redox regulator. HO-1 and GCLC are located downstream of Nrf2 and play important roles in intracellular redox balance as antioxidant enzymes (Bao et al., 2014; Silva et al., 2019; Deng et al., 2020; Ghosh et al., 2021). Some reports showed the balance between Nrf2/GSH antioxidant pathway and DNA repair might modulate cisplatin resistance in cancer cells (Qiu et al., 2020; Ghosh et al., 2021). The down-regulation of Nrf2 also corresponds to the decreased expression of its downstream targets HO-1 and GCLC, which suggest that DCTPP1 knockdown reduces cellular redox protection capacity through inhibiting the Nrf2 signaling pathway. Correspondingly, we have also observed a decline in the overall antioxidant capacity of cells in FRAP assay. At present, most reference believe that there is extensive interaction between the P13k/Akt signaling pathway and the Nrf2 pathway ( $\mathrm{Li}$ et al., 2020; Qiu et al., 2020). From our results, it is not certain whether the reduction in Akt and Nrf2 activation induced by shDCTPP1 occur independently of each other, or whether one is upstream of the other. We tend to think that DCTPP1 may act as a redox-protected protein to help ovarian cancer cells respond to cisplatin-induced changes in intracellular ROS.

In the following experiments, we demonstrated that the sensitivity of ovarian cancer cells to cisplatin can be increased by inhibiting DCTPP1. As shown in our results, under the pressure of cisplatin, DCTPP1 knockdown significantly increased the accumulation of intracellular ROS. DCTPP1 knockdown increases the sensitivity of ovarian cancer cells to cisplatin in cisplatin-sensitive cells, which is reflected in growth inhibition, increased levels of apoptosis and increased DNA damage. Therefore, we speculate that cisplatin stimulates the overexpression of DCTPP1 in ovarian cancer cells to stabilize

\section{REFERENCE}

Azzouz, D., Khan, M. A., and Palaniyar, N. (2021). ROS Induces NETosis by Oxidizing DNA and Initiating DNA Repair. Cell Death Discov 7 (1), 113. doi:10. 1038/s41420-021-00491-3

Bao, L. J., Jaramillo, M. C., Zhang, Z. B., Zheng, Y. X., Yao, M., Zhang, D. D., et al. (2014). Nrf2 Induces Cisplatin Resistance through Activation of Autophagy in Ovarian Carcinoma. Int. J. Clin. Exp. Pathol. 7 (4), 1502-1513. the accumulation of ROS in the cells, thereby protecting the cells from oxidative damage induced by cisplatin.

\section{CONCLUSION}

High expression of DCTPP1 is associated with malignancy of ovarian cancer, and its expression could be induced by cisplatin. Under the pressure of cisplatin,up-regulation of DCTPP1 will minimize the oxidative DNA damage caused by ROS -overload. The clinical strategy against DCTPP1 may help to enhance the prognosis of cisplatin chemotherapy.

\section{DATA AVAILABILITY STATEMENT}

The datasets presented in this study can be found in online repositories. The names of the repository/repositories and accession number(s) can be found in the article/Supplementary Material.

\section{ETHICS STATEMENT}

The studies involving human participants were reviewed and approved by ethics committee of Nanfang hospital, Southern medical university (Permit Number NFEC-2021-261). The patients/participants provided their written informed consent to participate in this study.

\section{AUTHOR CONTRIBUTIONS}

Conceived and designed the experiments: YC and LH. Performed the experiments: YW, PC, XC, and DG. Analyzed the data: YW and YC. Contributed reagents/materials/analysis tools: YW and XC. Wrote the paper: YC and PC.

\section{FUNDING}

This work was supported by grants from the National Natural Science Foundation of China (No. 81802610 and No. 81703078). This work was also supported by grants from Guangdong Province Science and Technology Project (No. 2017A010105025) (S2019154), Major Science and Technology Project of Guangdong Province (No: 2019B110233003) and the National Natural Science Foundation of China (No: 81773271).

Brett, R., Jennifer, P., and Thomas, S., (2017) Epidemiology of Ovarian Cancer: a Review. Cancer Biol. Med. 14(1), 9. doi:10.20892/j.issn.2095-3941.2016.0084

Deng, X., Lin, N., Fu, J., Xu, L., Luo, H., Jin, Y., et al. (2020). The Nrf2/PGC1alpha Pathway Regulates Antioxidant and Proteasomal Activity to Alter Cisplatin Sensitivity in Ovarian Cancer. Oxid. Med. Cel. Longev., 4830418. doi:10.1155/ 2020/4830418

Fruehauf, J. P., and Meyskens, F. J. (2007). Reactive Oxygen Species: a Breath of Life or Death. Clin. Cancer Res. 13 (3), 789-794. doi:10.1158/1078-0432.CCR-062082 
Ghosh, S., Dutta, N., Banerjee, P., Gajbhiye, R. L., Sareng, H. R., Kapse, P., et al. (2021). Induction of Monoamine Oxidase A-Mediated Oxidative Stress and Impairment of Nrf2-Antioxidant Defence Response by Polyphenol-Rich Fraction of Bergenia Ligulata Sensitizes Prostate Cancer Cells In Vitro and In Vivo. Free Radic. Biol. Med. 172, 136-151. doi:10.1016/j.freeradbiomed.2021. 05.037L

Girish, K. S., Paul, M., Thushara, R. M., Hemshekhar, M., Shanmuga, S. M., Rangappa, K. S., et al. (2013). Melatonin Elevates Apoptosis in Human Platelets via ROS Mediated Mitochondrial Damage. Biochem. Biophys. Res. Commun. 438 (1), 198-204. doi:10.1016/j.bbrc.2013.07.053

Glubb, D. M., Thompson, D. J., Aben, K., Alsulimani, A., Amant, F., Annibali, D., et al. (2021). Cross-Cancer Genome-wide Association Study of Endometrial Cancer and Epithelial Ovarian Cancer Identifies Genetic Risk Regions Associated with Risk of Both Cancers. Cancer Epidemiol. Biomarkers Prev. 30 (1), 217-228. doi:10.1158/1055-9965.EPI-20-0739

Han, Y., Kim, B., Cho, U., Park, I. S., Kim, S. I., Dhanasekaran, D. N., et al. (2019). Mitochondrial Fission Causes Cisplatin Resistance under Hypoxic Conditions via ROS in Ovarian Cancer Cells. Oncogene 38 (45), 7089-7105. doi:10.1038/ s41388-019-0949-5

Jang, H., Lee, O. H., Lee, Y., Yoon, H., Chang, E. M., Park, M., et al. (2016). Melatonin Prevents Cisplatin-Induced Primordial Follicle Loss via Suppression of PTEN/Akt/FOXO3a Pathway Activation in the Mouse Ovary. J. Pineal Res. 60 (3), 336-347. doi:10.1111/jpi.12316

Jaramillo, M. C., and Zhang, D. D. (2013). The Emerging Role of the Nrf2-Keap1 Signaling Pathway in Cancer. Genes Dev. 27 (20), 2179-2191. doi:10.1101/gad. 225680.113

Kleih, M., Bopple, K., Dong, M., Gaissler, A., Heine, S., Olayioye, M. A., et al. (2019). Direct Impact of Cisplatin on Mitochondria Induces ROS Production that Dictates Cell Fate of Ovarian Cancer Cells. Cell Death Dis 10 (11), 851. doi:10.1038/s41419-019-2081-4

Li, F., Wu, Y., Chen, L., Hu, L., Zhu, F., and He, Q. (2019). High Iodine Induces DNA Damage in Autoimmune Thyroiditis Partially by Inhibiting the DNA Repair Protein MTH1. Cell. Immunol. 344, 103948. doi:10.1016/j.cellimm.2019.103948

Li, P., Hu, J., Shi, B., and Tie, J. (2020). Baicalein Enhanced Cisplatin Sensitivity of Gastric Cancer Cells by Inducing Cell Apoptosis and Autophagy via Akt/mTOR and Nrf2/Keap 1 Pathway. Biochem. Biophys. Res. Commun. 531 (3), 320-327. doi:10.1016/j.bbrc.2020.07.045

Lu, J., Dong, W., He, H., Han, Z., Zhuo, Y., Mo, R., et al. (2018). Autophagy Induced by Overexpression of DCTPP1 Promotes Tumor Progression and Predicts Poor Clinical Outcome in Prostate Cancer. Int. J. Biol. Macromol. 118 (Pt A), 599-609. doi:10.1016/j.ijbiomac.2018.06.005

Marquard, F. E., and Jucker, M. (2020). PI3K/Akt/mTOR Signaling as a Molecular Target in Head and Neck Cancer. Biochem. Pharmacol. 172, 113729. doi:10. 1016/j.bcp.2019.113729

Martinez-Arribas, B., Requena, C. E., Perez-Moreno, G., Ruiz-Perez, L. M., Vidal, A. E., and Gonzalez-Pacanowska, D. (2020). DCTPP1 Prevents a Mutator Phenotype through the Modulation of dCTP, dTTP and dUTP Pools. Cell. Mol. Life Sci. 77 (8), 1645-1660. doi:10.1007/s00018-019-03250-x

Marullo, R., Werner, E., Degtyareva, N., Moore, B., Altavilla, G., Ramalingam, S. S., et al. (2013). Cisplatin Induces a Mitochondrial-ROS Response that Contributes to Cytotoxicity Depending on Mitochondrial Redox Status and Bioenergetic Functions. PLoS One 8 (11), e81162. doi:10.1371/journal.pone.0081162

Niu, M., Shan, M., Liu, Y., Song, Y., Han, J. G., Sun, S., et al. (2021). DCTPP1, an Oncogene Regulated by miR-378a-3p, Promotes Proliferation of Breast Cancer via DNA Repair Signaling Pathway. Front. Oncol. 11, 641931. doi:10.3389/fonc. 2021.641931

Pecsi, I., Szabo, J. E., Adams, S. D., Simon, I., Sellers, J. R., Vertessy, B. G., et al. (2011). Nucleotide Pyrophosphatase Employs a P-loop-like Motif to Enhance Catalytic Power and NDP/NTP Discrimination. Proc. Natl. Acad. Sci. U S A. 108 (35), 14437-14442. doi:10.1073/pnas.1013872108

Preya, U. H., Lee, K. T., Kim, N. J., Lee, J. Y., Jang, D. S., and Choi, J. H. (2017). The Natural Terthiophene Alpha-Terthienylmethanol Induces S Phase Cell Cycle Arrest of Human Ovarian Cancer Cells via the Generation of ROS Stress. Chem. Biol. Interact 272, 72-79. doi:10.1016/j.cbi.2017.05.011
Qiu, Z., Zhao, X., and Chen, H. (2020). DJ-1 Is Involved in the Multidrug Resistance of SGC7901 Gastric Cancer Cells through PTEN/PI3K/Akt/Nrf2 Pathway. Acta Biochim. Biophys. Sin (Shanghai) 52 (11), 1202-1214. doi:10. 1093/abbs/gmaa110

Rai, P. (2012). Human Mut T Homolog 1 (MTH1): a Roadblock for the TumorSuppressive Effects of Oncogenic RAS-Induced ROS. Small GTPases 3 (2), 120-125. doi:10.4161/sgtp.19556

Rai, P., and Sobol, R. W. (2019). Mechanisms of MTH1 Inhibition-Induced DNA Strand Breaks: The Slippery Slope from the Oxidized Nucleotide Pool to Genotoxic Damage. DNA Repair (Amst) 77, 18-26. doi:10.1016/j.dnarep. 2019.03.001

Rai, P., Young, J. J., Burton, D. G., Giribaldi, M. G., Onder, T. T., and Weinberg, R. A. (2011). Enhanced Elimination of Oxidized Guanine Nucleotides Inhibits Oncogenic RAS-Induced DNA Damage and Premature Senescence. Oncogene 30 (12), 1489-1496. doi:10.1038/onc.2010.520

Requena, C. E., Perez-Moreno, G., Ruiz-Perez, L. M., Vidal, A. E., and GonzalezPacanowska, D. (2014). The NTP Pyrophosphatase DCTPP1 Contributes to the Homoeostasis and Cleansing of the dNTP Pool in Human Cells. Biochem. J. 459 (1), 171-180. doi:10.1042/BJ20130894

Requena, E., Perez-Moreno, G., Horvath, A., Vertessy, B. G., Ruiz-Perez, L. M., Gonzalez-Pacanowska, D., et al. (2016). The Nucleotidohydrolases DCTPP1 and dUTPase Are Involved in the Cellular Response to Decitabine. Biochem. J. 473 (17), 2635-2643. doi:10.1042/BCJ20160302L

Silva, M. M., Rocha, C., Kinker, G. S., Pelegrini, A. L., and Menck, C. (2019). The Balance between Nrf2/GSH Antioxidant Mediated Pathway and DNA Repair Modulates Cisplatin Resistance in Lung Cancer Cells. Sci. Rep. 9 (1), 17639. doi:10.1038/s41598-019-54065-6

Srinivas, U. S., Tan, B., Vellayappan, B. A., and Jeyasekharan, A. D. (2019). ROS and the DNA Damage Response in Cancer. Redox Biol. 25, 101084. doi:10.1016/ j.redox.2018.101084

Vlahos, N. F., Kalampokas, T., and Fotiou, S. (2010). Endometriosis and Ovarian Cancer: a Review. Gynecol. Endocrinol. 26 (3), 213-219. doi:10.1080/ 09513590903184050

Wang, W., Im, J., Kim, S., Jang, S., Han, Y., Yang, K. M., et al. (2020). ROS-induced SIRT2 Upregulation Contributes to Cisplatin Sensitivity in Ovarian Cancer. Antioxidants (Basel) 9 (11), 37. doi:10.3390/antiox9111137

Webb, P. M., and Jordan, S. J. (2017). Epidemiology of Epithelial Ovarian Cancer. Best Pract. Res. Clin. Obstet. Gynaecol. 41, 3-14. doi:10.1016/j.bpobgyn.2016. 08.006

Wu, Y. H., Huang, Y. F., Chen, C. C., Huang, C. Y., and Chou, C. Y. (2020). Comparing PI3K/Akt Inhibitors Used in Ovarian Cancer Treatment. Front. Pharmacol. 11, 206. doi:10.3389/fphar.2020.00206

Xia, L., Tang, Y. B., Song, F. F., Xu, L., Ji, P., Wang, S. J., et al. (2016). DCTPP1 Attenuates the Sensitivity of Human Gastric Cancer Cells to 5-fluorouracil by Up-Regulating MDR1 Expression Epigenetically. Oncotarget 7 (42), 68623-68637. doi:10.18632/oncotarget.11864M

Conflict of Interest: The authors declare that the research was conducted in the absence of any commercial or financial relationships that could be construed as a potential conflict of interest.

Publisher's Note: All claims expressed in this article are solely those of the authors and do not necessarily represent those of their affiliated organizations, or those of the publisher, the editors, and the reviewers. Any product that may be evaluated in this article, or claim that may be made by its manufacturer, is not guaranteed or endorsed by the publisher.

Copyright (C) 2022 Wang, Chen, Chen, Gong, Wu, Huang and Chen. This is an openaccess article distributed under the terms of the Creative Commons Attribution License (CC BY). The use, distribution or reproduction in other forums is permitted, provided the original author(s) and the copyright owner(s) are credited and that the original publication in this journal is cited, in accordance with accepted academic practice. No use, distribution or reproduction is permitted which does not comply with these terms. 